07

\title{
Влияние бора на структуру и проводимость тонких пленок, получаемых лазерной абляцией алмаза при $700^{\circ} \mathrm{C}$
}

\author{
(С) Р.И. Романов ${ }^{1}$, В.Ю. Фоминский ${ }^{1,}$, П.В. Зинин ${ }^{2}$, И.А. Троян ${ }^{3}$, \\ Д.В. Фоминский ${ }^{1}$, П.С. Джумаев ${ }^{1}$, В.П. Филоненко \\ ${ }^{1}$ Национальный исследовательский ядерный университет „МИФИ“, \\ Москва, Россия \\ ${ }^{2}$ Научно-технологический центр уникального приборостроения РАН, \\ Москва, Россия \\ ${ }^{3}$ Федеральный научно-исследовательский центр „Кристаллография \\ и фотоника" РАН, Москва, Россия \\ ${ }^{4}$ Институт физики высоких давлений им. Л.Ф. Верещагина РАН, Москва, \\ Троицк, Россия \\ ฯE-mail: vyfominskij@mephi.ru
}

Поступило в Редакцию 2 марта 2018 г.

Исследованы структурные особенности тонких пленок $\mathrm{CB}_{x}$, полученных при импульсной лазерной абляции мишеней, изготовленных из прессованного алмазного порошка с добавлением порошка бора в соотношении атомов $\mathrm{B} / \mathrm{C}=0.33$. Осаждение пленок проводилось на нагретые подложки, что обусловливало возможность диффузионных процессов на поверхности и в объеме пленок с участием атомов С и В. Установлено, что выбранные условия получения пленок обеспечивали их эффективное легирование бором $(0.4 \leqslant x \leqslant 0.6)$. Внедрение атомов В сопровождалось образованием химических связей $\mathrm{B}-\mathrm{C}$, a формирование графитовых $s p^{2}$-связей и их упорядочение в нанокластеры с ламинарной упаковкой подавлялось. При комнатной температуре пленки обладали очень низким удельным сопротивлением $(\sim 1.4 \mathrm{~m} \Omega \cdot \mathrm{cm})$ и проявляли металлический тип проводимости при понижении температуры до $77 \mathrm{~K}$.

DOI: 10.21883/PJTF.2018.12.46286.17275

Известно, что при относительно небольшом содержании В (1-3 at.\%) электрофизические свойства алмаза существенно изменяются, и он может проявлять сверхпроводимость при температурах 4-11 K. 
Теоретические исследования показывают, что алмазы могут быть даже высокотемпературными сверхпроводниками с температурой перехода около $60 \mathrm{~K}$, если концентрация В в решетке составит $20-30 \%$ [1]. Синтез наногетероалмаза в условиях сверхвысоких давлений и температур подтвердил прогноз о том, что введение атомов В в алмаз не должно приводить к значительному искажению его кубической ячейки [2].

К настоящему времени наиболее высокие температуры перехода в сверхпроводящее состояние ( $~ 55 \mathrm{~K})$ обнаружены у пленок, полученных путем импульсного лазерного сплавления тонких чередующихся нанослоев В и алмазоподобного С [3]. Борсодержащие пленки С кроме сверхпроводящих характеристик могут проявлять целый комплекс интересных электрофизических, оптических и механических свойств [4], которые обусловливают интенсивное развитие исследований тонкопленочных (наномасштабированных) метастабильных материалов $\mathrm{CB}_{x}$ наряду с изучением „массивных“, в том числе микроструктурированных, материалов на основе гетероалмазов.

Для получения тонкопленочных материалов $\mathrm{CB}_{x}$ используются различные методы химического и физического осаждения из паровой фазы, включая импульсное лазерное осаждение (ИЛО). Применение ИЛО обусловливает ряд специфических эффектов, которые привлекают особое внимание к этому методу $[5,6]$. Можно отметить гибкость метода в получении различных по локальному состоянию алмазоподобных структур и возможность варьирования отношения В/C в широких пределах. Анализ результатов ряда работ (например, $[3,4]$ ) показал, что интересные и важные свойства пленок $\mathrm{CB}_{x}$ могут реализоваться в метастабильных состояниях, для формирования которых не требуется экстремальной неравновесности процессов. Скорость охлаждения жидкой фазы, используемой для получения сверхпроводящих пенок из смеси C-B в [3], может составлять $\sim 10^{10} \mathrm{~K} / \mathrm{s}$ [7]. Диссипация энергии при охлаждении паровой фазы (конденсация лазерного факела) и в тепловых пиках (внедрение ионов лазерного факела) протекает гораздо быстрее $[7,8]$, если ИЛО проводится при нормальных условиях.

Цель настоящей работы заключается в изучении структурообразования пленок $\mathrm{CB}_{x}$, получаемых методом ИЛО на подогретую подложку, когда изменяется кинетика транспортных и химических процессов, а также в исследовании электрофизических свойств этих пленок. В настоящее время подавляющее число работ по ИЛО алмазоподобных пленок выполнено с применением мишеней из графита. При лазерной абляции

2 Письма в ЖТФ, 2018, том 44, вып. 12 
таких мишеней могут образовываться атомные кластеры, которые после осаждения на подложку оказывают определенное влияние на локальную структуру пленки, способствуя росту графитовых кластеров. Для исключения этого эффекта в данной работе лазерной абляции подвергалась мишень, полученная из порошков алмаза и бора, а пленка $\mathrm{CB}_{x}$ осаждалась на подложку, нагретую до $700^{\circ} \mathrm{C}$. Такая температура может активировать как процессы диффузии В в углеродной матрице пленки и ее структурную модификацию [4], так и формирование $s p^{2}$-связей между атомами С [9].

Для получения пленок $\mathrm{CB}_{x}$ использовался лазер на алюмоиттриевом гранате, излучающий на четвертой гармонике (длина волны $266 \mathrm{~nm}$ ). Энергия излучения в импульсе наносекундной длительности достигала $40 \mathrm{~mJ}$, плотность энергии в зоне абляции составляла $\sim 7 \mathrm{~J} / \mathrm{cm}^{2}$. Для получения пленок из аморфного углерода $(a-C)$ облучалась мишень из графита, а для получения пленок $\mathrm{CB}_{x}$ использовалась мишень, содержащая частицы алмаза размером до $1 \mu \mathrm{m}(75 \%)$ и бора размером до $5 \mu \mathrm{m}(25 \%)$, т.е. состав мишени описывался формулой $\mathrm{CB}_{0.33}$. Осаждение проводилось в вакуумной камере при давлении $\sim 10^{-3} \mathrm{~Pa}$.

Пленки, осажденные на кристаллы соли $\mathrm{NaCl}$ за $2.5 \mathrm{~min}$, переносились в воде на металлические сетки и исследовались методами просвечивающей электронной микроскопии (ПЭМ) и микродифракции (МД), спектроскопии характеристических потерь энергии электронов (ХПЭЭ), энергодисперсионной рентгеновской спектроскопии (ЭРС). ЭРС-измерения показали, что состав полученных пленок $\mathrm{CB}_{x}$ отличался от состава мишени в сторону повышенной концентрации бора $(x \sim 0.4)$. Пленки $\mathrm{CB}_{x}$ имели аморфную структуру (рис. 1), картина МД которой отличалась от картины МД для пленок $a$-С. Внедрение В снижало интенсивность отражения, соответствующего координационной сфере с радиусом $\sim 0.4 \mathrm{~nm}$, и вызывало диффузное уширение других рефлексов, соответствующих сферам с меньшим радиусом. Отражение, отвечающее наибольшему межатомному расстоянию, обусловлено, вероятно, дифракцией на кластерах с ламинарной упаковкой плоскостей (наноразмерных графеновых кластерах) [9]. Изменения картины МД указывало на то, что атомы В препятствовали процессам локального упорядочения, которые протекали в пленках $a$-C.

На вставке к рис. 1 приведены спектры ХПЭЭ в области плазмонных потерь для полученных пленок. Видно, что при внедрении В происходит сдвиг пика в область бо́льших энергий. Частота плазмонов

Письма в ЖТФ, 2018, том 44, вып. 12 


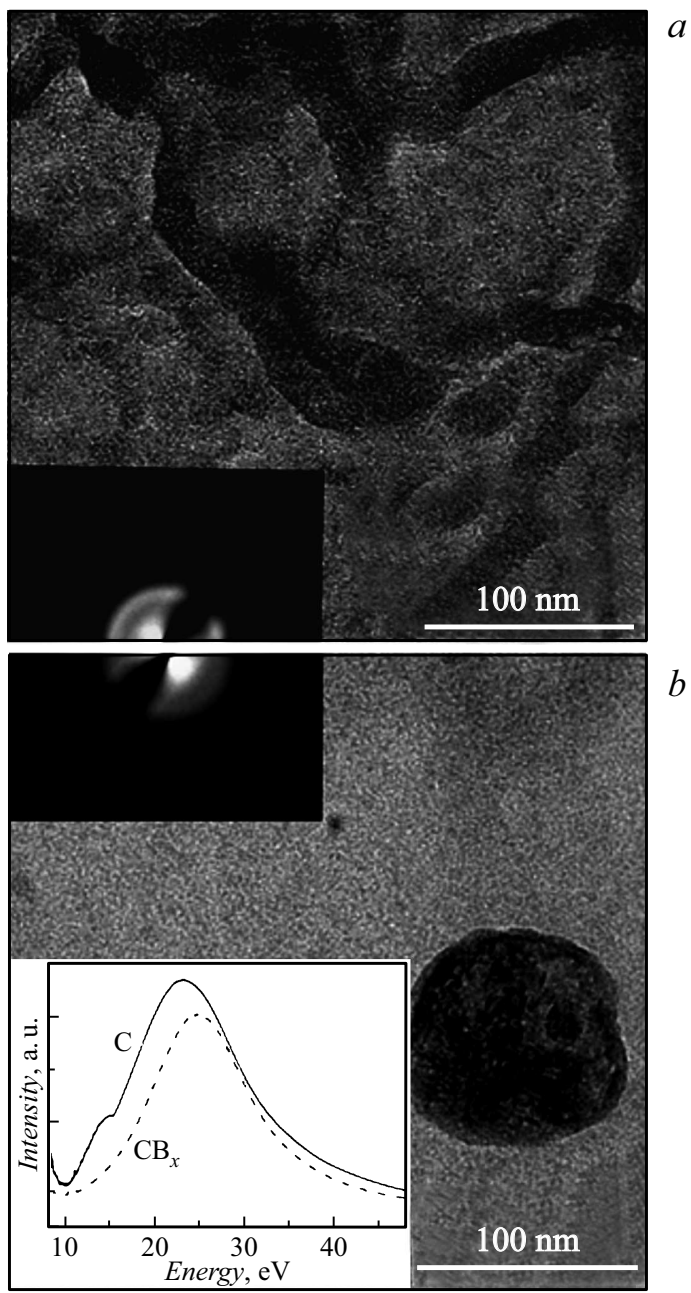

Рис. 1. Изображения ПЭМ и МД для пленок $a$-С $(a)$ и $\mathrm{CB}_{x}(b)$, полученных методом ИЛО с использованием графитовой и В-алмазной мишеней соответственно. На вставке приведены спектры ХПЭЭ в области плазмонных потерь.

2* Письма в ЖТФ, 2018, том 44, вып. 12 


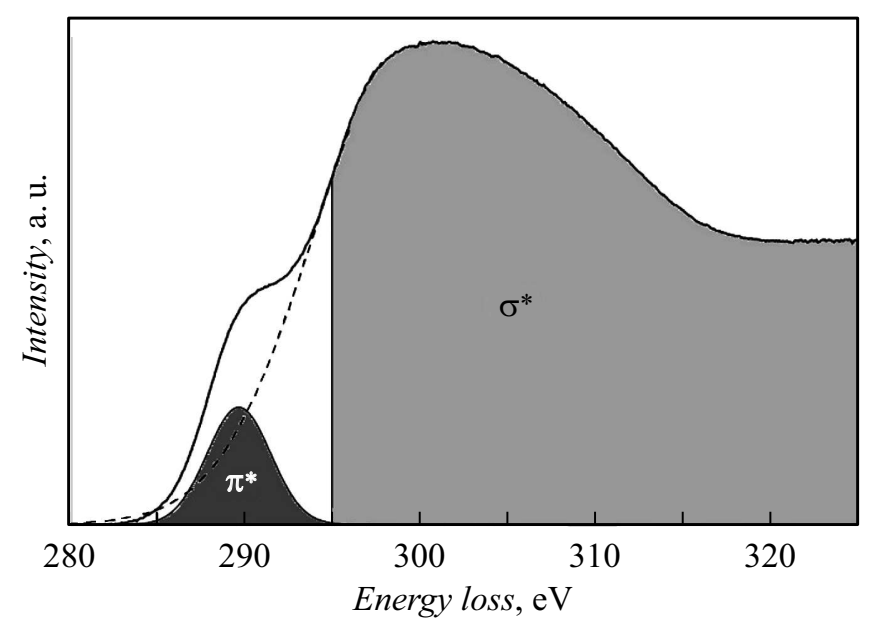

Рис. 2. Анализ спектров ХПЭЭ для определения отношения $s p^{2} / s p^{3}$-связей атомов в полученных пленках. Приведено разложение $K$-края С-полосы потерь на $\pi^{*}$ - и $\sigma^{*}$-электронах.

связана с электронной плотностью и зависит от двух конкурирующих факторов. С одной стороны, увеличение концентрации $s p^{3}$-состояний ведет к росту электронной плотности и сопровождается сдвигом пика плазмонных потерь в сторону бо́льших энергий. С другой стороны, увеличение концентрации В в пленках С может приводить к сдвигу пика в сторону меньших энергий. Это объясняется модификацией электронной структуры валентной зоны [10].

На рис. 2 представлены характерные результаты исследований пленок $\mathrm{CB}_{x}$ методом спектроскопии ХПЭЭ в области взаимодействия анализирующего пучка с углеродом. Для обработки спектров использовалась традиционная методика, которая позволяет оценить концентрацию $s p^{2}$ - и $s p^{3}$-связей в углеродной матрице пленки. В измеренных спектрах выделялись потери электронов анализирующего пучка на $\pi^{*}$ и $\sigma^{*}$-электронах пленки. Отношение площадей $R$ этих пиков определяло концентрацию $X s p^{2}$-связей: $X\left(s p^{2}\right)=4 R /(1+R)$. Концентрация $s p^{3}$-связей рассчитывалась как $X\left(s p^{3}\right)=1-X\left(s p^{2}\right)$. Анализ показал, что в пленке $a$-С концентрация $s p^{3}$-связей составляла $\sim 0.7$, а в пленке $\mathrm{CB}_{x}$ она увеличивалась до 0.8 . 
Для исследования электрофизических свойств создавались более толстые пленки $\mathrm{CB}_{x}$ методом ИЛО на кремниевые пластины. Время осаждения увеличивалось до $30 \mathrm{~min}$. Исследование этих пленок методом сканирующей электронной микроскопии показало, что пленки имели плотную структуру с гладкой поверхностью, на которой располагались отдельные частицы В субмикронных размеров. Анализ поперечного сечения пленок методом сканирующей электронной микроскопии позволил оценить толщину этих пленок, которая составляла $\sim 90 \mathrm{~nm}$. Согласно результатам ЭРС-измерений, эти пленки были еще в большей степени обогащены бором $(x \sim 0.6)$, чем более тонкие пленки.

Результаты анализа состава пленок $\mathrm{CB}_{x}$, получаемых методом ИЛО из В-алмазной мишени, показали, что импульсная лазерная абляция такой мишени может протекать специфическим образом. В случае применения В-графитовых мишеней, как правило, отмечается преимущественное осаждение С. Потери В объясняются возможностью его преимущественного распыления осаждаемым потоком атомов В и С. Также отмечается склонность к формированию крупных частиц В в процессе абляции В-графитовых мишеней, что значительно снижает концентрацию В в паровой (атомарной) фракции лазерного факела [5]. Потери С при лазерной абляции В-алмазных мишеней могли быть обусловлены отрывом алмазных частиц от поверхности мишени и увеличением содержания В в поверхностном слое. Поскольку крупные алмазные частицы не обнаружены в большом количестве на поверхности пленки $\mathrm{CB}_{x}$, они либо плохо прилипали к ее поверхности, либо разлетались в большой телесный угол по сравнению с углом разлета атомарной фракции.

Измерение спектров рентгеновской фотоэлектронной спектроскопии (РФЭС) проводилось на поверхности пленки $\mathrm{CB}_{x}$ до и после (рис. 3) ионного травления. На исходной поверхности пленки в спектре РФЭС доминировали линии от загрязнений $\mathrm{C}-\mathrm{O}$ и $\mathrm{C}-\mathrm{H}$. Эти загрязнения удалялись ионным распылением, однако ионно-инициированное перемешивание могло вызвать определенные изменения в химическом составе поверхности и обусловить транспортные процессы, в частности внедрение атомов $\mathrm{O}$ в глубь пленки $\mathrm{CB}_{x}$. При разложении спектра $\mathrm{C} 1 s$ после ионного травления выявлены состояния, отвечающие связям $\mathrm{C}-\mathrm{B}(283.3 \mathrm{eV}$, линия 1$), s p^{2}$ - $(284.2 \mathrm{eV}$, линия 2$)$ и $s p^{3}$-связям $(285 \mathrm{eV}$, линия 3) атомов С. Линия 4 при энергиях связи более $286.5 \mathrm{eV}$ соответствовала связям $\mathrm{C}-\mathrm{O}$ и $\mathrm{C}-\mathrm{O}-\mathrm{C}$. При разложении спектра $\mathrm{B} 1 s$

Письма в ЖТФ, 2018, том 44, вып. 12 

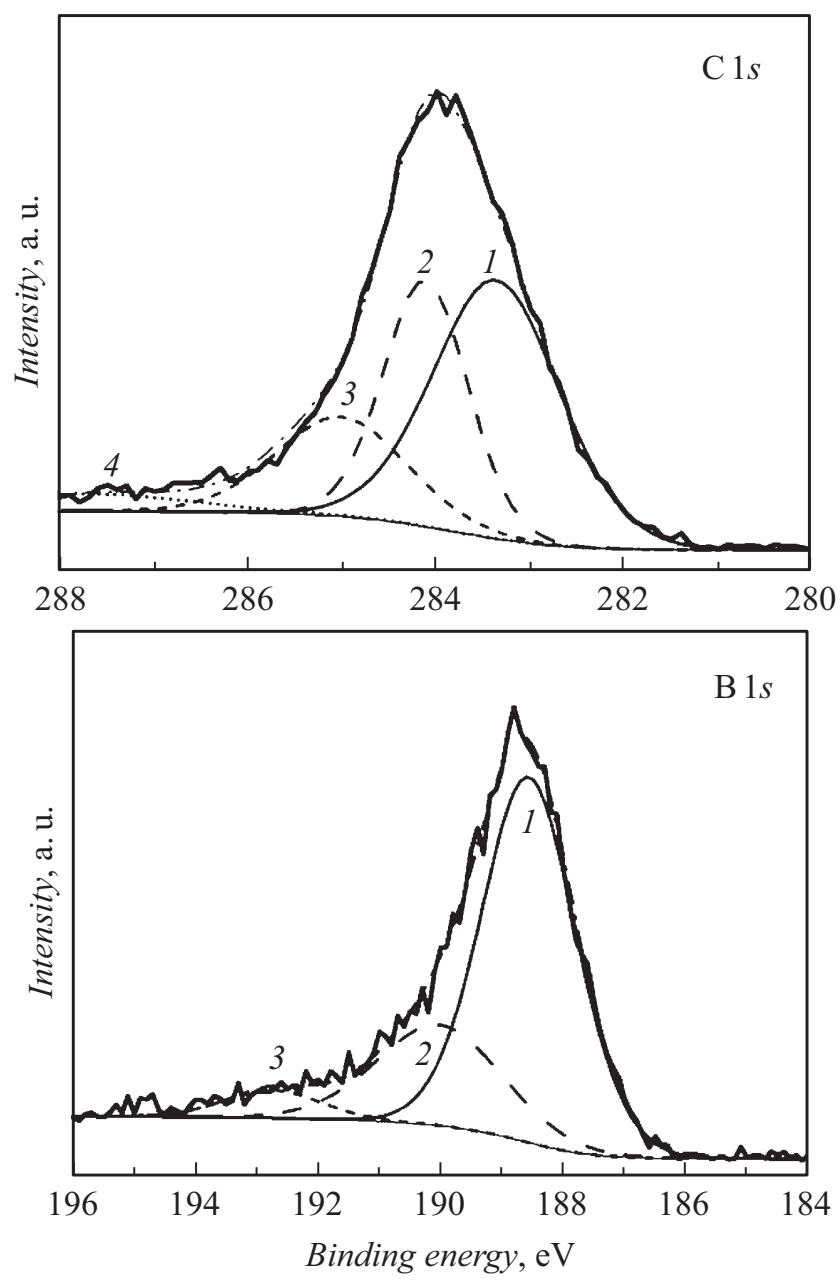

Pис. 3. Участки спектров РФЭС для элементов С и В, измеренные после ионной очистки поверхности пленок $\mathrm{CB}_{x}$ (пояснения даны в тексте).

выделены пики, отвечающие В, встроенному в матрицу C $(188.8 \mathrm{eV}$, линия 1$)$, а также ряду тройных соединений $\mathrm{B}-\mathrm{C}-\mathrm{O}(190.0$ и $192.0 \mathrm{eV}$, линии 2 и 3 соответственно). РФЭС-исследования подтвердили, что 
соосаждение В и С при повышенной температуре обеспечивало эффективное смешивание этих атомов в аморфной пленке $\mathrm{CB}_{x}$, что исключало образование кластеров В.

Измерения удельного сопротивления пленок $\mathrm{CB}_{x}$ проводились методом Ван-дер-Пау. При $300 \mathrm{~K}$ сопротивление не превышало $1.4 \mathrm{~m} \Omega \cdot \mathrm{cm}$. Согласно анализу опубликованных данных, такое значение является рекордно низким для алмазоподобных пленок, содержащих В (обзор опубликованных результатов приведен в [4]). Зависимость тока от напряжения носила линейный характер. В диапазоне температур $300-77 \mathrm{~K}$ обнаружен металлический ход удельного сопротивления, обусловливающий его уменьшение до $0.2 \mathrm{~m} \Omega \cdot \mathrm{cm}$ при низких температурах.

Таким образом, импульсная лазерная абляция мишени, содержащей микрочастицы алмаза и бора, позволяла получить при температуре $700^{\circ} \mathrm{C}$ относительно гладкие пленки $\mathrm{CB}_{x}$, концентрация В в которых превышала его концентрацию в мишени. Внедрение атомов В $(0.4 \leqslant x \leqslant 0.6)$ способствовало формированию разупорядоченной структуры с повышенной концентрацией $s p^{3}$-связей в матрице $\mathrm{C}$. Аморфные пленки $\mathrm{CB}_{x}$ обладали низким удельным сопротивлением и металлическим типом проводимости, что отличало свойства полученных в работе пленок $\mathrm{CB}_{x}$ от приведенных в литературе свойств В-содержащих алмазоподобных пленок и указывало на потенциальную возможность расширения области практического применения пленок такого типа.

Работа выполнена при финансовой поддержке РНФ (грант 17-1201535). В.Ю. Фоминский благодарит Министерство образования и науки РФ за поддержку в рамках работы „Организация проведения научных исследований“. И.А. Троян благодарит Федеральное агентство научных организаций за поддержку в рамках соглашения № 007-ГЗ/Ч3363/26.

\section{Список литературы}

[1] Moussa J.E., Cohen M.L. // Phys. Rev. B. 2008. V. 77. N 6. P. 064518.

[2] Zinin P.V., Ming L.C., Ishii H.A., Jia R., Acosta T., Hellebrand E. // J. Appl. Phys. 2012. V. 111. Iss. 11. P. 114905.

[3] Bhaumik A., Sachan R., Gupta S., Narayan J. // ACS Nano. 2017. V. 11. Iss. 12. P. 11915-11922.

Письма в ЖТФ, 2018, том 44, вып. 12 
[4] Song W., Kim Y., Jung D.S., Lee S., Jung W., Kwon O., Kim H.K., Kim M.S., An K.S., Park C.-Y. // Appl. Surf. Sci. 2013. V. 284. P. 53-58.

[5] Zhang S., He Z., Ji X., Lu W., Wang C., Shen Q., Zhang L. // J. Appl. Phys. 2014. V. 115. Iss. 15. P. 154906.

[6] Nakazawa H., Osozawa R., Mohnai Y., Nara Y. // Jpn. J. Appl. Phys. 2017. V. 56. N 10. P. 105501.

[7] Быковский Ю.А., Неволин В.Н., Фоминский В.Ю. Ионная и лазерная имплантация металлических материалов. М.: Энергоатомиздат, 1991. $237 \mathrm{c.}$

[8] Фоминский В.Ю., Григорьев С.Н., Гнедовеи А.Г., Романов Р.И. // Письма в ЖТФ. 2012. Т. 38. В. 14. C. 86-94.

[9] Cappelli E., Scilletta C., Orlando S., Flammini R., Iacobucci S., Ascarelli P. // Thin Solid Films. 2005. V. 482. Iss. 1-2. P. 305-310.

[10] Sikora A., Bourgeois O., Sanchez-Lopez J.C., Rouzaud J.-N., Rojas T.C., Loir A.-S., Garden J.-L., Garrelie F., Donnet C. // Thin Solid Films. 2009. V. 518. Iss. 5. P. $1470-1474$. 